\title{
Functional Remediation for Bipolar Disorder
}

\author{
Anabel Martínez-Arán ${ }^{1}$, Carla Torrent ${ }^{2}$, Brisa Solé ${ }^{2}$, C. Mar Bonnín ${ }^{2}$, Adriane R. Rosa ${ }^{2}$, \\ José Sánchez-Moreno ${ }^{2}$ and Eduard Vieta ${ }^{2} *$
}

\author{
${ }^{I}$ Early Onset Psychosis Program \& Bipolar Disorders Program, Clinical Institute of Neuroscience, Hospital Clinic of \\ Barcelona, IDIBAPS, CIBERSAM, Barcelona, Spain \\ ${ }^{2}$ Bipolar Disorders Program, Clinical Institute of Neuroscience, Hospital Clinic of Barcelona, Psychiatry Department, \\ University of Barcelona, IDIBAPS, CIBERSAM, Barcelona, Spain
}

\begin{abstract}
Neurocognitive impairment constitutes a core feature of bipolar illness. The main domains affected are verbal memory, attention, and executive functions. Deficits in these areas as well as difficulties to get functional remission seem to be increased associated with illness progression. Several studies have found a strong relationship between neurocognitive impairment and low functioning in bipolar disorder, as previously reported in other illnesses such as schizophrenia. Cognitive remediation strategies, adapted from work conducted with traumatic brain injury patients and applied to patients with schizophrenia, also need to be adapted to individuals with bipolar disorders. Early intervention using functional remediation, involves neurocognitive techniques and training, but also psychoeducation on cognition-related issues and problem-solving within an ecological framework.
\end{abstract}

Keywords: Neurocognition, functional remediation, bipolar disorder.

\section{INTRODUCTION}

The term "functional remediation" refers to interventions aimed at restoring psychosocial functioning in patients with brain disorders, including, obviously, mental disorders, by means of ecological neurocognitive techniques. The term "ecological" tries to emphasize the practical effectiveness of those interventions on daily life, as opposed to other, which may be criticised as of being closer to "brain training" rather than real functioning. Functional remediation involves psychoeducation about cognitive dysfunctions and their impact on the general functioning.

\section{NEUROCOGNITIVE IMPAIRMENT IN BIPOLAR DISORDER}

In the last decade we have seen that cognitive impairment is a core feature of bipolar illness. Cognitive deficits persist during euthymia and may include attention, executive function, and verbal memory impairment [1-5]. These cognitive dysfunctions may reflect abnormal activation patterns in the brain $[6,7]$, involving the prefrontal cortex in the etiopathogenesis of bipolar illness and positing cortical-subcorticallimbic disruption as the underlying cause $[8,9]$. Such deficits do not seem to be specific and their pattern is quite similar to schizophrenia, albeit overall less severe [10, 11]. Euthymic bipolar patients demonstrate relatively marked impairment in aspects of executive function and verbal memory [1]. It is not clear yet whether these are two discrete

\footnotetext{
*Address correspondence to this author at the Bipolar Disorders Program, Hospital of Barcelona, CIBERSAM. Villarroel 170, 08036-Barcelona, Spain; Tel: +34 93 2275401; Fax: +34 932275795;

E-mail: evieta@clinic.ub.es
}

areas of impairment or whether such deficits are related one to another. In addition, is yet to be determined whether neuropsychological impairment is already present before the clinical onset of the disorder, although several studies suggest that bipolar patients may be relatively preserved from the neurocognitive point of view before developing their condition. Several studies have looked in different ways at the cognitive performance of large cohorts of children or youth and analyzed the specific profile of those who would subsequently develop bipolar disorder or schizophrenia; overall, there is no suggestion for severe deficits prior to onset of bipolar disorder, whereas there seems to be so for schizophrenia [12-14] perhaps with the exception of visuospatial reasoning [15]. Interestingly, subjects at risk for bipolar disorder were more likely than subjects at risk for schizophrenia and even than subjects at no risk for mental disorders to perform better in some domains [14], particularly at arithmetic reasoning [15]. Neuropsychological studies on first-degree relatives of subjects with bipolar disorder, though, suggest that there might be some mild deficits underlying vulnerability to the disorder in the areas of psychomotor speed and executive function [16-18], but not verbal memory [19]. In fact, verbal memory was not found to be related to increased risk for bipolar disorder in premorbid neuropsychological studies [15], but seems to be strongly affected by the impact of multiple episodes [3], subthreshold depressive symptoms [20], and medication [21-24]. Hence, verbal memory may be a potential treatment target by means of effective prophylactic treatment, improvement of subclinical depressive symptoms, and rational use of medication. Importantly, verbal memory performance has been reported to be highly correlated with functional outcome [25-27]. 
Neurocognitive impairment may not occur exclusively in individuals with bipolar type I disorder, as it has been reported in bipolar II disorder [28], schizoaffective disorder bipolar type [29], bipolar patients with and without history of psychosis [22, 30, 31], bipolar suicide attempters [32], bipolar patients with comorbid conditions [33-35], and pediatric bipolar disorder [36]. On the other hand, a subset of bipolar patients seems to have little or no cognitive impairment [37]. In general, between $40 \%$ and $60 \%$ of bipolar patients show neurocognitive deficits in early phases of the illness [38] and deficits are more marked in those patients with more relapses [39]. Thus, the study of bipolar subtypes and subgroups, including those who do not show cognitive deficits, may provide important clues for the effective treatment and prevention of cognitive impairment and psychosocial dysfunction.

\section{IMPACT OF NEUROCOGNITIVE IMPAIRMENT ON FUNCTIONING}

There is an increasing evidence of a relationship between cognitive impairment and low functioning in bipolar patients. The experience in schizophrenic patients can help to clear that neurocognitive functioning may be more strongly associated with functional outcome than clinical symptoms. In this case, and especially during the last decade, several studies have pointed out to the correlation between the performance on specific cognitive tasks and lower psychosocial functioning assessed through general measures, such as the GAF [40]. Most of these studies tried to control for the impact of subclinical symptoms that have been considered as a negative influence for the functional recovery of bipolar patients. One of the main problems is that remission and euthymia criteria are often not clearly defined, so differences between studies were found [41] .

In recent studies, an association between CVLT verbal memory measures and low functioning was consistently found [3, 27, 42, 43]. Poor planning and problem solving were associated with functioning, so that difficulties with logical approaches to problems in daily living may have the greatest impact in functional outcome [44]. Other executive function measures correlated with social disability, but weakly [45]. TMT-B was also found to be a good correlate of functioning in bipolar I and II patients [28]. Recent publications also reported that executive function performance was related to employment status [46]. Moreover, a connection between the RBANS immediate memory performance and the current work status was also reported [47].

Jaeger and Vieta [48] co-edited a special issue on functionality in Bipolar Disorders, including four studies linking cognition and functioning. WCST categories correlated with GAF scores [49]. Dittmann et al. [50] reported that psychosocial functioning was significantly correlated with working memory measures. Martinez-Aran et al. [25] found that CVLT verbal recall was the measure that best predicted psychosocial functioning. Finally, Jaeger et al. [51] looked for predictors of functional remission one year after discharge due to an acute episode. Attention and ideational fluency were the factors that best predicted functioning. In this line, another study showed that the Neurocognitive Global Index and, specifically, speed of processing were the best predictors of functional remission at one-year follow-up [52]. Per- sistent deficits in verbal memory, executive functions and attention may lead to impairments in occupational, social and interpersonal functioning, so we should optimize not only cognitive but also functional measures. There are very few longitudinal studies focused on the analysis of predictive factors of functioning in bipolar disorder. Discrepancies on the findings from different studies emphasize the need for consensus on the assessment of bipolar patients. The development of core-sets for bipolar disorder, based on the International Classification of Functioning, Disability and Health (ICF), may be useful in further research [53]. The ISBDBANC is promoting a consensus battery for the neurocognitive assessment of bipolar patients as well [54]. Moreover, the use of brief instruments focused on specific functional areas affected in bipolar patients, will allow identify correlates of different areas of functioning [55]. The cognitive measures found to be associated with functioning vary between studies and, in general, they have not been found to be strongly correlated. Findings seem to be quite consistent with regard to the relevance of verbal learning and memory measures, such as the California Verbal Learning Test on disability, using the FAST, in longer longitudinal studies [27]. Interestingly, recent findings suggest that executive function measures may also play an essential role on functioning and disability [56]. In this regard, Murray et al. [57] have focused on specific self-management strategies used by high functioning individuals with bipolar disorder in order to maintain or regain wellness, including sleep, diet, rest and exercise, ongoing monitoring, reflective and meditative practices, understanding bipolar disorder and educating others, connecting to others and enacting a plan to prevent relapses. These findings suggest that patients receiving psychoeducation may be more likely to achieve functional recovery [58, 59]. A combination of psychoeducation and functional remediation may be helpful to foster recovery in these patients, taking into account that a neurodegenerative process can lead to poorer functioning in the long-term (see Fig. 1).

\section{COGNITIVE REMEDIATION VERSUS FUNC- TIONAL REMEDIATION}

Cognitive remediation (CR) has been extensively used for patients with schizophrenia and psychosis. Nevertheless, to our knowledge, there are only five CR studies including affective, bipolar and unipolar, patients [60-64] but only one of them was focused on bipolar patients [60], in other two studies the number of bipolar patients included were not specified $[65,66]$. The sample size of these studies ranges from 2 to 18 patients, which is really small, and the duration of interventions goes from 8 to 48 weeks. In general, CR programmes have used cognitive measures pre and post intervention to assess the efficacy of the intervention. More recently, CR has moved beyond cognitive enhancement, trying to reduce disability and improve functioning. McGurk et al. [67] reported that effects of CR on psychosocial functioning were significantly stronger in studies that also provided psychiatric rehabilitation.

Functional remediation (FR) covers not only cognition but also functioning, including psychoeducation about cognitive deficits and their impact on daily life, providing strategies to manage cognitive deficiencies in different cognitive domains, mainly in attention, memory and executive func- 


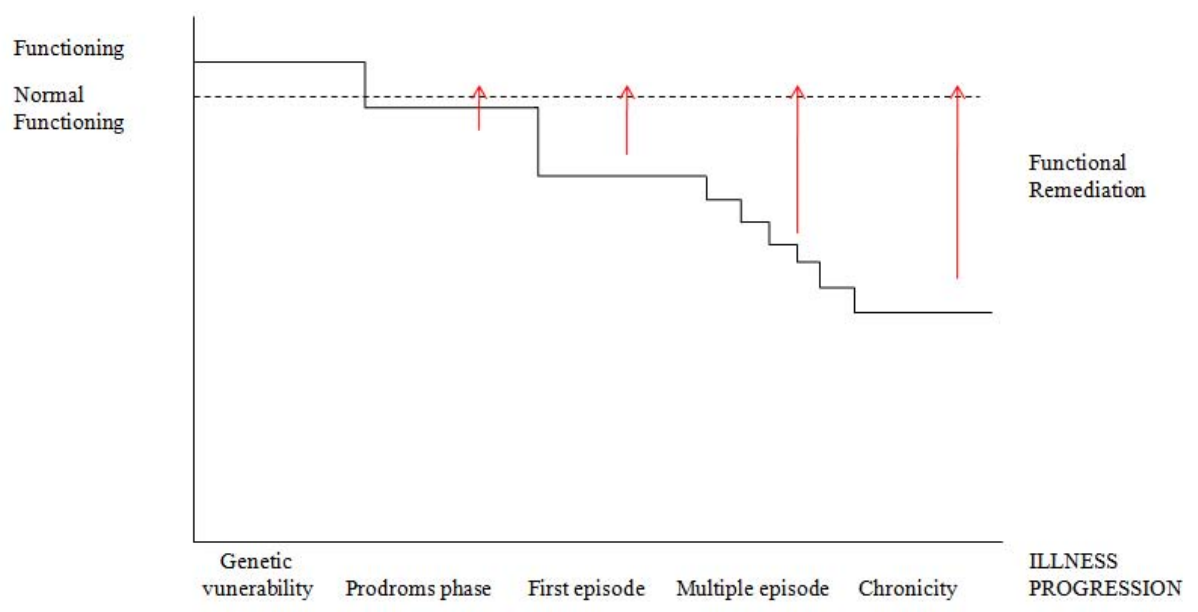

Fig. (1). Functional remediation tries to cover the gap between normal functioning and low functioning associated with illness progression. Functioning probably would be higher before illness onset, and some mild difficulties would be appreciated in the prodromal phase. Moderate difficulties in functioning are observed after the first manic episode since patients get clinical remission but most of them do not achieve premorbid functional recovery. A higher number of relapses would have a negative impact on the general functioning of bipolar patients.

tions. Family is involved in the process to facilitate practice of strategies and reinforcement. In the context of the Barcelona Bipolar Disorder Programme [68], the FR programme for bipolar disorder has been developed, consisting in 21 weekly sessions of 90 minutes of duration that includes 3 sessions of psychoeducation, 2 sessions to improve attention in everyday situations, 6 sessions focused on techniques and strategies to manage memory deficits and 5 more addressed to executive dysfunctions, especially problem solving, time management, planning and establishing priorities. Sessions are practical including daily life examples, individual and group tasks, role-playings and taking home practical exercises. The remaining sessions are related to improve communication and interpersonal relationships, autonomy and stress management. The effectiveness of the programme is assessed not only through a comprehensive neuropsychological battery but also through measures of functionality, disability, and quality of life, such as the FAST, WHODAS-II and SF-36. These tools help us to establish the nature of the problems, and to analyse changes selecting, as outcome variable, the FAST [55, 69]. Clearly, we do not try to just treat the inability to perform a particular neurocognitive test, since an improvement on such a test is not the best way of measuring real-life outcomes [70].

A neuro-cognitive-behavioral approach has been taken into consideration in order to plan this FR programme addressed to bipolar disorder, so that, modelling techniques, role-playing, verbal instructions, self-instructions, positive reinforcement and meta-cognitive cues, among others, have been included. We need to combine theories, methodologies and approaches in order to enhance not only cognition but also functioning in these patients due to the complexity and severity of bipolar disorder, but especially to prevent or reduce neuroprogression.

\section{CONCLUSIONS}

Although cognitive rehabilitation is currently being explored in an attempt to improve the neurocognitive perform- ance of schizophrenic as well as bipolar patients, and ultimately their functional outcome, we have coined the term "functional remediation" to define an innovative strategy aimed at targeting the critical factors for full psychosocial adjustment and functional recovery in the context of psychoses and, more specifically, manic-depressive illness. Functional remediation involves neurocognitive techniques and training, but also psychoeducation on cognition-related issues and problem-solving within an ecological framework. The inclusion of context processing, performance monitoring, encoding and manipulation of the information as well as foster compensatory strategies must be included in the FR intervention. In this regard, real-world problems affecting daily functioning are used in FR for bipolar disorder to be transferred to daily practice. A clinical trial assessing the effectiveness of this strategy is on the way, using as primary outcome a functionality measure.

\section{REFERENCES}

[1] Robinson LJ, Thompson JM, Gallagher P, et al. A meta-analysis of cognitive deficits in euthymic patients with bipolar disorder. J Affect Disord 2006; 93:105-15.

[2] Mur M, Portella MJ, Martinez-Aran A, Pifarre J, Vieta E Persistent neuropsychological deficit in euthymic bipolar patients: executive function as a core deficit. J Clin Psychiatry 2007; 68:1078-86.

[3] Martinez-Aran A, Vieta E, Colom F, et al. Cognitive impairment in euthymic bipolar patients: implications for clinical and functional outcome. Bipolar Disord 2004; 6: 224-32.

[4] Arts B, Jabben N, Krabbendam L, van Os J. Meta-analyses of cognitive functioning in euthymic bipolar patients and their firstdegree relatives. Psychol Med 2008; 38: 771-85.

[5] Bora E, Yucel M, Pantelis C. Cognitive endophenotypes of bipolar disorder: a meta-analysis of neuropsychological deficits in euthymic patients and their first-degree relatives. J Affect Disord 2009; 113: 1-20.

[6] Strakowski SM, Adler CM, Holland SK, Mills NP, Delbello MP Eliassen JC. Abnormal FMRI brain activation in euthymic bipolar disorder patients during a counting stroop interference task. Am J Psychiatry 2005; 162: 1697-705.

[7] Benabarre A, Vieta E, Martinez-Aran A, et al. Neuropsychological disturbances and cerebral blood flow in bipolar disorder. Aust N Z J Psychiatry 2005; 39: 227-34. 
[8] Olley A, Malhi GS, Mitchell PB, Batchelor J, Lagopoulos J, Austin MP. When Euthymia is just not good enough: the neuropsychology of bipolar disorder. J Nerv Ment Dis 2005; 193: 323-30.

[9] Malhi GS, Ivanovski B, Szekeres V, Olley A. Bipolar disorder: it's all in your mind? The neuropsychological profile of a biological disorder. Can J Psychiatry 2004; 49: 813-9.

[10] Daban C, Martinez-Aran A, Torrent C, et al. Specificity of cognitive deficits in bipolar disorder versus schizophrenia: a systematic review. Psychother Psychosom 2006; 75: 72-84.

[11] Goodwin GM, Martinez-Aran A, Glahn DC, Vieta E. Cognitive impairment in bipolar disorder: neurodevelopment or neurodegeneration? An ECNP expert meeting report. Eur Neuropsychopharmacol 2008; 18: 787-93.

[12] Zammit S, Allebeck P, David AS, et al. A longitudinal study of premorbid IQ Score and risk of developing schizophrenia, bipolar disorder, severe depression, and other nonaffective psychoses. Arch Gen Psychiatry 2004; 61: 354-60.

[13] Reichenberg A, Weiser M, Rabinowitz J, et al. A population-based cohort study of premorbid intellectual, language, and behavioral functioning in patients with schizophrenia, schizoaffective disorder, and nonpsychotic bipolar disorder. Am J Psychiatry 2002; 159: 2027-35.

[14] Cannon TD, Rosso IM. Levels of analysis in etiological research on schizophrenia. Dev Psychopathol 2002; 14: 653-66.

[15] Tiihonen J, Haukka J, Henriksson M, et al. Premorbid intellectual functioning in bipolar disorder and schizophrenia: results from a cohort study of male conscripts. Am J Psychiatry 2005;162: 190410.

[16] Antila M, Tuulio-Henriksson A, Kieseppa T, Eerola M, Partonen T, Lonnqvist J. Cognitive functioning in patients with familial bipolar I disorder and their unaffected relatives. Psychol Med 2007; 37: 679-87.

[17] Balanza-Martinez V, Rubio C, Selva-Vera G, et al. Neurocognitive endophenotypes (endophenocognitypes) from studies of relatives of bipolar disorder subjects: a systematic review. Neurosci Biobehav Rev 2008; 32: 1426-38.

[18] Szoke A, Schurhoff F, Golmard JL, et al. Familial resemblance for executive functions in families of schizophrenic and bipolar patients. Psychiatry Res 2006; 144: 131-8.

[19] Clark L, Sarna A, Goodwin GM. Impairment of executive function but not memory in first-degree relatives of patients with bipolar I disorder and in euthymic patients with unipolar depression. Am J Psychiatry 2005; 162:1980-2.

[20] McKay AP, Tarbuck AF, Shapleske J, McKenna PJ. Neuropsychological function in manic-depressive psychosis. Evidence for persistent deficits in patients with chronic, severe illness. Br J Psychiatry 1995; 167: 51-7.

[21] Martinez-Aran A, Vieta E, Colom F, et al. Do cognitive complaints in euthymic bipolar patients reflect objective cognitive impairment? Psychother Psychosom 2005; 74: 295-302.

[22] Bora E, Vahip S, Akdeniz F, et al. The effect of previous psychotic mood episodes on cognitive impairment in euthymic bipolar patients. Bipolar Disord 2007; 9: 468-77.

[23] Vieta E. The influence of medications on neurocognition in bipolar disorder. Acta Psychiatr Scand 2009; 120: 414-5.

[24] Balanza-Martinez V, Selva G, Martinez-Aran A, et al. Neurocognition in bipolar disorders--a closer look at comorbidities and medications. Eur J Pharmacol 2010; 626: 87-96.

[25] Martinez-Aran A, Vieta E, Torrent C, et al. Functional outcome in bipolar disorder: the role of clinical and cognitive factors. Bipolar Disord 2007; 9: 103-13.

[26] Altshuler LL, Bearden CE, Green MF, van Gorp W, Mintz J. A relationship between neurocognitive impairment and functional impairment in bipolar disorder: a pilot study. Psychiatry Res 2008; 157: 289-93.

[27] Bonnin CM, Martinez-Aran A, Torrent C, et al. Clinical and neurocognitive predictors of functional outcome in bipolar euthymic patients: a long-term, follow-up study. J Affect Disord 2010; 121: 156-60.

[28] Torrent C, Martinez-Aran A, Daban C, et al. Cognitive impairment in bipolar II disorder. Br J Psychiatry 2006; 189: 254-9.

[29] Torrent C, Martinez-Aran A, Amann B, et al. Cognitive impairment in schizoaffective disorder: a comparison with nonpsychotic bipolar and healthy subjects. Acta Psychiatr Scand 2007; 116: 453-60.
[30] Selva G, Salazar J, Balanza-Martinez V, et al. Bipolar I patients with and without a history of psychotic symptoms: do they differ in their cognitive functioning? J Psychiatr Res 2007; 41: 265-72.

[31] Martinez-Aran A, Torrent C, Tabares-Seisdedos R, et al. Neurocognitive impairment in bipolar patients with and without history of psychosis. J Clin Psychiatry 2008; 69: 233-9.

[32] Harkavy-Friedman JM, Keilp JG, Grunebaum MF, et al. Are BPI and BPII suicide attempters distinct neuropsychologically? J Affect Disord 2006; 94: 255-9.

[33] van Gorp WG, Altshuler L, Theberge DC, Wilkins J, Dixon W. Cognitive impairment in euthymic bipolar patients with and without prior alcohol dependence: a preliminary study. Arch Gen Psychiatry 1998; 55: 41-6.

[34] Rucklidge JJ. Impact of ADHD on the neurocognitive functioning of adolescents with bipolar disorder. Biol Psychiatry 2006; 60, 9218

[35] Sanchez-Moreno J, Martinez-Aran A, Colom F, et al. Neurocognitive dysfunctions in euthymic bipolar patients with and without prior history of alcohol use. J Clin Psychiatry 2009; 70(8): 1120-7.

[36] Pavuluri MN, Schenkel LS, Aryal S, et al. Neurocognitive function in unmedicated manic and medicated euthymic pediatric bipolar patients. Am J Psychiatry 2006; 163: 286-93.

[37] Altshuler LL, Ventura J, van Gorp WG, Green MF, Theberge DC, Mintz J. Neurocognitive function in clinically stable men with bipolar I disorder or schizophrenia and normal control subjects. Biol Psychiatry 2004; 56: 560-9.

[38] Reichenberg A, Harvey PD, Bowie CR, et al. Neuropsychological function and dysfunction in schizophrenia and psychotic affective disorders. Schizophr Bull 2009; 35: 1022-9.

[39] Lopez-Jaramillo C, Lopera-Vasquez J, Gallo A, et al. Effects of recurrence on the cognitive performance of patients with bipolar I disorder: implications for relapse prevention and treatment adherence. Bipolar Disord 2010; 12: 557-67.

[40] Forcada I, Papachristou E, Mur M, et al. The impact of general intellectual ability and white matter volume on the functional outcome of patients with Bipolar Disorder and their relatives. J Affect Disord 2011; 130(3): 413-20.

[41] Martinez-Aran A, Vieta E, Chengappa KN, Gershon S, Mullen J, Paulsson B. Reporting outcomes in clinical trials for bipolar disorder: a commentary and suggestions for change. Bipolar Disord 2008; 10: 566-79.

[42] Zubieta JK, Huguelet P, O'Neil RL, Giordani B. Cognitive function in euthymic bipolar I disorder. Psychiatry Res 2001; 102: 9-20.

[43] Martinez-Aran A, Vieta E, Reinares M, et al. Cognitive function across manic or hypomanic, depressed, and euthymic states in bipolar disorder. Am J Psychiatry 2004; 161: 262-70.

[44] Laes JR, Sponheim SR. Does cognition predict community function only in schizophrenia?: a study of schizophrenia patients, bipolar affective disorder patients, and community control subjects. Schizophr Res 2006; 84: 121-31.

[45] Goswami U, Sharma A, Khastigir U, et al. Neuropsychological dysfunction, soft neurological signs and social disability in euthymic patients with bipolar disorder. Br J Psychiatry 2006; 188: 366-73.

[46] Altshuler L, Tekell J, Biswas K, et al. Executive function and employment status among veterans with bipolar disorder. Psychiatr Serv 2007; 58: 1441-7.

[47] Dickerson FB, Boronow JJ, Stallings CR, Origoni AE, Cole S, Yolken RH. Association between cognitive functioning and employment status of persons with bipolar disorder. Psychiatr Serv 2004; 55: 54-8.

[48] Jaeger J, Vieta E. Functional outcome and disability in bipolar disorders: ongoing research and future directions. Bipolar Disord 2007; 9: 1-2.

[49] Malhi GS, Ivanovski B, Hadzi-Pavlovic D, Mitchell PB, Vieta E, Sachdev P. Neuropsychological deficits and functional impairment in bipolar depression, hypomania and euthymia. Bipolar Disord 2007; 9: 114-25.

[50] Dittmann S, Seemuller F, Schwarz MJ, et al. Association of cognitive deficits with elevated homocysteine levels in euthymic bipolar patients and its impact on psychosocial functioning: preliminary results. Bipolar Disord 2007; 9: 63-70.

[51] Jaeger J, Berns S, Loftus S, Gonzalez C, Czobor P. Neurocognitive test performance predicts functional recovery from acute 
exacerbation leading to hospitalization in bipolar disorder. Bipolar Disord 2007;9:93-102.

[52] Tabares-Seisdedos R, Balanza-Martinez V, Sanchez-Moreno J, et al. Neurocognitive and clinical predictors of functional outcome in patients with schizophrenia and bipolar I disorder at one-year follow-up. J Affect Disord 2008; 109: 286-99.

[53] Vieta E, Cieza A, Stucki G, et al. Developing core sets for persons with bipolar disorder based on the International classification of functioning, disability and health. Bipolar Disord 2007; 9: 16-24.

[54] Yatham LN, Torres IJ, Malhi GS, et al. The International Society for Bipolar Disorders-Battery for Assessment of Neurocognition (ISBD-BANC). Bipolar Disord 2010; 12: 351-63.

[55] Rosa AR, Sanchez-Moreno J, Martinez-Aran A, et al. Validity and reliability of the Functioning Assessment Short Test (FAST) in bipolar disorder. Clin Pract Epidemol Ment Health 2007; 3: 5.

[56] Martino DJ, Marengo E, Igoa A, Scapola M, Ais ED, Perinot L, Strejilevich SA. Neurocognitive and symptomatic predictors of functional outcome in bipolar disorders: a prospective 1 year follow-up study. J Affect Disord 2009; 116: 37-42.

[57] Murray G, Harvey A. Circadian rhythms and sleep in bipolar disorder. Bipolar Disord 2010; 12: 459-72.

[58] Colom F, Vieta E, Martinez-Aran A, et al. A randomized trial on the efficacy of group psychoeducation in the prophylaxis of recurrences in bipolar patients whose disease is in remission. Arch Gen Psychiatry 2003; 60: 402-7.

[59] Colom F, Vieta E, Sanchez-Moreno J, et al. Group psychoeducation for stabilised bipolar disorders: 5-year outcome of a randomised clinical trial. Br J Psychiatry 2009;194: 260-265.

[60] Deckersbach T, Nierenberg AA, Kessler R, et al. RESEARCH: Cognitive rehabilitation for bipolar disorder: An open trial for employed patients with residual depressive symptoms. CNS Neurosci Ther 2010; 16: 298-307.
[61] Spaulding WD, Reed D, Sullivan M, Richardson C, Weiler M. Effects of cognitive treatment in psychiatric rehabilitation. Schizophr Bull 1999; 25: 657-76.

[62] Naismith SL, Redoblado-Hodge MA, Lewis SJ, Scott EM, Hickie IB. Cognitive training in affective disorders improves memory: a preliminary study using the NEAR approach. J Affect Disord 2010; 121: $258-62$.

[63] Ueland T, Rund BR. Cognitive remediation for adolescents with early onset psychosis: a 1-year follow-up study. Acta Psychiatr Scand 2005; 111: 193-201.

[64] McGurk SR, Mueser KT, DeRosa TJ, Wolfe R. Work, recovery, and comorbidity in schizophrenia: a randomized controlled trial of cognitive remediation. Schizophr Bull 2009; 35: 319-35.

[65] Meusel LA, McKinnon M, Hall G, MacQueen GM. Evidence for sustained improvement in memory deficits following computerassisted cognitive remediation in patients with a mood disorder. Biological Psychiatry's 64th Annual Scientifgic Convention. Biol Psychiatry 2009; 65: 234S.

[66] Choi J, Medalia A. Factors associated with a positive response to cognitive remediation in a community psychiatric sample. Psychiatr Serv 2005; 56: 602-4.

[67] McGurk SR, Mueser KT, Feldman K, Wolfe R, Pascaris A. Cognitive training for supported employment: 2-3 year outcomes of a randomized controlled trial. Am J Psychiatry 2007; 164: 437-41.

[68] Vieta E. Tertiarism in Psychiatry: The Barcelona "Clinic" Bipolar Disorders Programme. Rev Psiquiatr Salud Ment (Barc). 2011; 4: $1-4$

[69] Rosa AR, Bonnin CM, Mazzarini L, Amann B, Kapczinski F, Vieta E. Predictores clínicos del funcionamiento interpersonal en pacientes bipolares. Rev Psiquiatr Salud Ment (Barc) 2009; 2: 83-8.

[70] Wilson BA, Herbert CM, Shiel A. Behavioural Approaches in Neuropsychological Rehabilitation: Optimizing Rehabilitation Procedures. New York: Psychological Press 2003.

(C) Martínez-Arán et al.; Licensee Bentham Open.

This is an open access article licensed under the terms of the Creative Commons Attribution Non-Commercial License (http://creativecommons.org/licenses/by-nc/3.0/) which permits unrestricted, non-commercial use, distribution and reproduction in any medium, provided the work is properly cited. 